\title{
BRILLO DE CANDILEJAS: EMILIA PARDO BAZÁN, BENITO PÉREZ GALDÓS, CLARÍN Y EL TEATRO ${ }^{1}$
}

\author{
JAVIER LÓPEZ QUINTÁNS
}

IES Ramón María Aller Ulloa, Lalín, Pontevedra

\begin{abstract}
Resumen
Las colaboraciones periodísticas de Galdós, Clarín y Pardo Bazán constituyen un testimonio inestimable de lo que fue el panorama teatral español entre los años 1864 y 1910. Su mirada crítica abarca dimensiones múltiples de dicho espectro: público, crítica, autores, actores e intentos de renovación frustrados (la reforma de Stanislavski o el Teatro Libre). El artículo busca poner en paralelo los juicios de los tres autores, manifestándose las muchas concordancias y sintonías.
\end{abstract}

Palabras clave: teatro, siglo XIX, Galdós, Clarín, Pardo Bazán, colaboraciones periodísticas.

\begin{abstract}
The journalistic Galdós, Clarín, and Pardo Bazán is an invaluable witness to what was the Spanish theater scene between 1864 and 1910. His critical view encompasses multiple dimensions of the spectrum: public, critics, authors, actors and frustrated attempts to renew (the breath of the reform of Stanislavsky or the Teatro Libre). This article seeks to parallel the trials of the three authors, demonstrating the many commonalities and affinities.
\end{abstract}

Key words: theater, the nineteenth century, Galdós, Clarín, Pardo Bazán, journalistic articles.

La relación personal entre los tres protagonistas de este artículo, Galdós, Clarín y Pardo Bazán, ha suscitado comentarios de diversa naturaleza, así como trabajos que trataban de perfilar los entendimientos y discrepancias entre tales figuras. Nos mueve ahora un objetivo que, quizás no tan estimulante como las indagaciones bienintencionadas sobre sus motivadoras vidas, tratará en cualquier caso de aportar algo más de luz a las concomitancias que de su concepción sobre el universo literario ofrecen los tres creadores. Es esta la estela con la que se pretende rastrear la visión del teatro de Galdós y Pardo Bazán, para proceder de inmediato a compararla con la de Clarín. Las matizaciones de don Benito y Leopoldo Alas aportan comentarios (de los manejados, por su relevancia) más tempranos (el primer documento que se coteja es del año 1864) que se mantienen constantes en el tiempo. La autora gallega ofrece una significativa afinidad con ellos en notas tan diversas como el teatro en tanto que

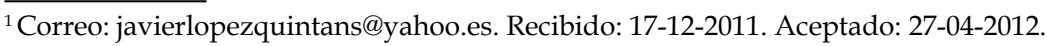


espectáculo, como universo lleno de intereses encontrados, como ámbito bajo el yugo del exigente y variopinto público.

Los tres proponen opiniones inestimables para entender el panorama teatral español de los años que corren de 1862 a 1910. El innegable interés de ponerlos en proximidad se incrementa ante las posibilidades de trazar un acercamiento, bajo su atenta mirada, de lo que fue el teatro español de finales del XIX y principios del siglo XX. En el caso de Galdós hemos advertido la relevancia de las colaboraciones en $\mathrm{La}$ Nación. Diario progresista, de las que han sido esenciales una treintena de trabajos publicados entre 1865 y 1868, y las cartas del autor a La Prensa de Buenos Aires. Se alude asimismo a una decena de referencias que se mueven entre los años 1884 y 1889: Nuestro Teatro (1885-1887); los prólogos a Los condenados (1894) y a El caballero encantado (1909); así como otros textos dispersos, recogidos en la edición de inéditos en 1923 de Alberto Ghiraldo (véase bibliografía).

La amplísima producción periodística de Clarín alberga abundante información sobre el teatro. Su recorrido nos ha permitido extraer interesantes comentarios en más de setenta colaboraciones con una visión clara del panorama teatral del momento. Se percibe una postura sólida, coherente, que se configura con los años. Con el empeño de que el lector conozca la conformación y evolución de los postulados del autor ovetense, se precisan las décadas en las que tales trabajos se forjan, desde los años 70 hasta su muerte prematura, a principios del siglo XX.

En el caso de Emilia Pardo Bazán, se ha recurrido a alusiones dispersas en El lirismo en la poesía francesa, junto con las colaboraciones en La Ilustración Artística de Barcelona (diez artículos entre los años 1900 y 1911); las colaboraciones en el Diario de la Marina de La Habana (seis crónicas entre 1900 y 1915); las colaboraciones en La Nación de Buenos Aires (diez trabajos entre 1909 y 1911); una colaboración en La Ilustración Ibérica de 1884; y otra en $A B C$, de 1910.

Al cabo, las reflexiones de los tres autores muestran un amplio abanico temporal (1860-1910) en el que se desliza una visión concomitante acerca del mundo del teatro.

\section{PANORAMA TEATRAL}

Las dificultades declasificación del teatro delosimprecisamentellamados autores realistas-naturalistas son evidentes, dada la variedad de su producción. Los estertores del drama romántico no se encauzan en la renovación teatral que se experimenta en numerosos países europeos. Durante el período romántico, sobresale la preocupación por renovar el mundo del teatro (así lo defiende en numerosas ocasiones Mariano José de Larra). No prosperan tales esperanzadoras pretensiones, frente a lo que se venía haciendo en Europa. Son los tres autores que nos ocupan prueba de la admiración que se sentía ante intentos renovadores de etiqueta extranjera, esos mismos intentos que en España provocaron el desaliento de grupos intelectuales frente a los gustos y políticas teatrales dominantes. Más allá de nuestros Pirineos Stanislavski (1863-1938) participa de la fundación en 1888 de la Sociedad de Artes y Letras, un puntal iniciático 
que despuntaba como pionero intento de conformar un nuevo teatro, renovador y de calidad. Sin embargo, es la fundación del Teatro de Arte de Moscú a finales del siglo XIX la que manifiesta aires revolucionarios, pues se erige como revulsivo contra la idiosincrasia del teatro a la moda, inmovilista y anticuado. Este fenómeno tiene su eco en España sin que prosperen iniciativas similares.

No fueron tampoco ajenos a los intentos renovadores de otras figuras como la de Chéjov (1860-1904), ligado al personaje que acabamos de señalar, Stanislavski (el Teatro de Arte representa en 1898 La Gaviota, a la que seguirían El Tío Vania o El jardín de los cerezos). Chéjov asume el uso de la técnica que bautiza bajo el sintagma de «acción indirecta», un procedimiento que otorgaba gran relevancia a la intervención de los personajes (mientras que la propia trama ocupaba posición secundaria) al mismo tiempo que adquiría peso lo que se sobreentendía y sucedía fuera de escena.

La situación en España, a finales del XIX, era bien diferente. Al contrario de los intentos de Stanislavski o Chéjov, predominaba una dramaturgia anquilosada, sumisa ante los gustos de un público burgués ajeno a aventuras innovadoras. Es llamativa la ausencia de una necesaria renovación teatral en la época de Galdós, Clarín y Pardo Bazán. Son sus palabras las que nos permiten aventurar las tendencias en boga: melodramas, comedias de ambiente contemporáneo, tragedias de magisterio clásico, el teatro musical (la zarzuela por excelencia) o diversidad de géneros menores (sainetes, vodeviles, operetas, cuplés y otros tantos de similar condición, como las "melocomedias" o "melopanoramas", en palabras de Clarín²). Los artículos seleccionados perfilan diversas fases en el desarrollo del teatro: según Galdós y Clarín, hasta los años 80 predominaban obras de contenido pseudohistórico, creaciones pseudorománticas, textos de tono didáctico, dramas de trasfondo truculento, obras de contenido patriótico, melodramas, producciones con trasluz moralizante, obras de tesis (que plantean un problema moral y un desenlace edificante), e imitaciones del teatro calderoniano. El Estado no interviene ni favorece las actividades teatrales, lo que conduce a una interesante polémica en la prensa de la época (tal es el caso de que se discuta la necesidad de la gestión del Teatro Español por parte del Ayuntamiento de Madrid).

Asimismo, conforme nos adentramos en los últimos años del siglo XIX abundan posturas dispares sobre fórmulas de renovación teatral, como así acontece con lo relacionado con el Teatro Libre. Nos fijamos, por tanto, en un momento en que triunfan las obras de López de Ayala (1828-1879), Tamayo y Baus (1829-1898), Enrique Gaspar (1842-1902), José de Echegaray (1832-1916), Leopoldo Cano (1844-1934), Eugenio Sellés (1844-1926), Feliú y Codina (1847-1897), Joaquín Dicenta (1863-1917), los hermános Álvarez Quintero o Benavente (1866-1954), entre otros, además de un grupo de autores de segunda fila que se irán conociendo en las siguientes líneas. Al grupo de los elegidos por el público se suman el propio Galdós, Clarín (de manera esporádica y discutida, con Teresa) y Pardo Bazán (con La suerte o Verdad, igual de discutida que Clarín -si

\footnotetext{
${ }^{2}$ «Noticias teatrales», El mundo moderno, 23, 22 de marzo de 1881.
} 
bien en provincias disfrutó de cierta aceptación; son, sin embargo, obras de notoria medianía, frente a las piezas, por ejemplo, de Galdós).

Las tendencias que se delimitaban muestran vicios que nuestros cronistas atacan, en busca de una expurgación necesaria que dé aliento al teatro. De especial relevancia y agudo sentido crítico son los pasajes clarinianos en los que censura obras de pecados impenitentes y autores mediocres. Estos pecados se traducen en tramas disparatadas, golpes de efecto mil veces vistos, un argumento inverosímil y enrevesado, un estilo mediocre o una predisposición clamorosa a la complacencia de los gustos del público (repetitivos e insustanciales, deseosos de motivos tópicos, como las continuas muertes en escena ${ }^{3}$ ). De la mano de Clarín podemos aventurar un tímido esbozo de lo que los programas teatrales ofrecían, y al tiempo comprender qué obras se aproximaban a su visión de un teatro con futuro. Abusando, así pues, de la paciencia del lector, ofrecemos esta información como extracto documental de lo que se viene diciendo. Censurables son para Leopoldo Alas, en los 70, Hermenegildo, de Francisco Sánchez de Castro; Roque Guinart, de Francisco Coello; El estómago, de J. Gaspar; Epílogo de una historia de Luis de San Juan; La Mariposa (obra que goza de repetido interés por su parte) de Leopoldo Cano, La mancha en la frente, de Ceferino Suárez Bravo; Lo que vale el talento, de Francisco Pérez Echevarría; El azote de Dios, de Gómez de Cádiz, Los trapos de cristianar, de Campoarana y Estremera, Pedro Fernández de Gaspar, Despertar en la sombra o El casino de Cavestany. Con defectos pero estimables, Maldades que son justicia, de Sellés; Vida por honra de Félix Aramburu y Zuloaga, algunos dramas históricos de Marcos Zapata en los 70; La Esfinge de Feuillet, Un viaje de recreo de Gondinet y Bisson, Divorsiamo o Los amigos de Sardou.

En los 80, vapulea Lazos eternos de Luis Calvo, Los Dengues de la niña, María Rosa, de Guimerá, María del Carmen, de Feliú y Codina; La justicia del acaso, de Emilio Ferrari, o Lo que no ve la justicia de Bremón, entre otros. Descubre algún elemento positivo en Las esculturas de carne o Cleopatra, de Sellés, o en algunas comedias de Rafael Calvo o de los hermanos Álvarez Quintero.

El recelo del autor ante las manifestaciones de mayor predicación popular es frecuente. Tengamos en cuenta en este momento que Clarín rechaza el teatro de Arderius ${ }^{4}$ y su esencia, y que la pluma del escritor «vetustense» censura la construcción de comedias inverosímiles consagradas a un cúmulo de dislates; para él, no respetan la esencia de la auténtica comedia, como la forjaron los clásicos. Recela por ello del teatro de su época, el que busca mezclar comedia y drama sin estar a la altura del gran Lope. Serán los años los que le revelen las posibilidades del Teatro Libre al modo parisién ${ }^{5}$; de un teatro de ensayo, en sus palabras, como reflexionará arrastrado por los

\footnotetext{
${ }^{3}$ «Los estrenos», La Unión, 332, 28 de octubre de 1879; «Palique», La Unión, 340, 6 de noviembre de 1879; «Teatros», La Unión, 344, 11 de noviembre de 1879; «Teatros», La Unión, 346, 13 de noviembre de 1879; «Teatros», La Unión, 347, 14 de noviembre de 1879; «Teatros», La Unión, 358, 27 de noviembre de 1879.

${ }^{4}$ «Palique», La Publicidad, 1313, 29 de septiembre de 1881; «Palique», Madrid Cómico, 12, 23 de diciembre de 1899 .

${ }^{5}$ «Revista mínima», La Publicidad, 5893, 24 de marzo de 1895; «Tribuna literaria», Los Lunes del Imparcial, 7 y 13 de julio de 1896; «Palique», Madrid cómico, 700, 18 de julio de 1896; «Palique», Heraldo de Madrid,
} 
debates intelectuales de la prensa en torno a este tema. Fundado en 1887 por André Antoine, el Teatro Libre se convierte en molde de una forma de teatro independiente que influye en el ruso Stanislavki o en el alemán Otto Brahm. Es un molde ajeno a los circuitos habituales, que implicaba nuevos valores y textos no consagrados por crítica y público. Precisamente por ello, suscitó numerosas suspicacias y recelos en la España del momento, matices en su recepción (aunque influye en compañías como la de María Guerrero) y discusiones dispares en la prensa. Unos ecos sobre el Teatro Libre de los que beben rotativos como La Ilustración Artística ${ }^{6}$, La Dinastía ${ }^{7}$, La Iberia ${ }^{8}$, La Correspondencia de España ${ }^{9}$, La España Moderna ${ }^{10}$, La Época ${ }^{11}$, Gedeón $^{12}$, El Imparcial ${ }^{13}$, La Ilustración Ibérica ${ }^{14}$, El Liberal ${ }^{15}$, Revista contemporánea ${ }^{16}$, El Siglo Futuro ${ }^{17}$ o La Ilustración Española y Americana ${ }^{18}$, entre otros.

Por lo tanto, se deduce que son males del teatro, en suma, el tono melodramático, los golpes de efecto innecesarios, el tono grandilocuente y la trama inverosímil, como se dijo. Clarín añade la falta de preparación de los autores dramáticos, y denuncia (tan de su gusto) sus carencias en el uso de la gramática. Con ello se gesta su reivindicación de la necesidad de una formación sólida.

Las quejas de Clarín no eran una gota en un océano. En el mismo camino, su antigua amiga Emilia Pardo Bazán, a principios del siglo XX, sistematizaba de forma pesimista el panorama teatral, aludiendo a aquellas obras destinadas a la complacencia del público burgués. Eran en gran medida comedias, junto a otras producciones menores en las que primaba la música y el espectáculo intrascendente ${ }^{19}$. A nuestro

\section{4, 3 de agosto de 1896.}

${ }^{6} 22$ de febrero de 1892, 13 de marzo de 1893, 12 de noviembre de 1894, 31 de agosto de 1896, 21 de septiembre de 1903.

${ }^{7} 27$ de octubre de 1888; 14 de abril de 1896.

${ }^{8} 4$ de diciembre de 1894, 30 de enero de 1898, 15 de julio de 1896, etc.

${ }^{9}$ Véanse los números de 11 de enero de 1891; 12 y 29de diciembre de 1894; 13 de abril, 25 de mayo y 30 de octubre de 1896; 17 y 23 de marzo, 2 de abril y 14 de noviembre de 1898; 1 de enero y 13 de diciembre de 1899; 26 de febrero de 1901; 12 de junio y 13 de septiembre de 1903; etc.

${ }^{10} 1$ de septiembre de 1893, 1 de enero de 1894, 1 de agosto de 1896.

${ }^{11} 15$ de octubre, 12 de noviembre de 1887; 27 de mayo de 1890; 11 de junio y 20 de diciembre de 1891; 29 de marzo de 1892; 17 de abril de 1894, 31 de agosto de 1896.

1216 de julio de 1897, 6 de agosto de 1896, 24 de abril de 1898, 3 de febrero de 1908, etc.

${ }^{13} 16$ de junio de 1890, 15 y 26 de enero de 1891, 9 de febrero de 1892, 6 y 13 de julio y 17 de agosto de 1896, 27 de mayo y 6 de junio de 1903.

${ }^{14} 10$ de octubre de 1896; 8 de mayo de 1897; 23 de abril de 1898.

${ }^{15} 9$ de mayo y 22 de noviembre de 1889; 25 de junio de 1894; 9 de febrero de 1899.

${ }^{16}$ Número 110.

${ }^{17} 27$ de noviembre de 1890, 15 de enero de 1910.

${ }^{18} 8$ y 30 de agosto, 15 de octubre de 1896.

19 «Crónica. Teatros y público», en La Nación, Buenos Aires, domingo 6 de junio de 1909; cito por la edición de Juliana Sinovas Maté, pág. 263. 
juicio, este amplio abanico de manifestaciones teatrales guarda estrecha relación con la diversidad de fuentes de las que beben los autores de este momento: el teatro de los Siglos de Oro español, el romántico (de elevada relevancia, frente a los engendros pseudorománticos de la época que les tocó vivir), la importancia del teatro de Echegaray, el creciente impulso de demanda de un público consumidor de géneros populares, y sin duda las diversas influencias extranjeras, dígase Ibsen (comentado con oscilantes reticencias en los artículos críticos de Clarín, Galdós o Pardo Bazán), pero también el teatro naturalista francés, el simbolista en la línea de Maeterlinck (con el que está en deuda, con bastante seguridad, Pardo Bazán, en textos como Verdad o Las raíces); o el teatro inglés con una figura fundamental del tipo de Óscar Wilde, cuyos estrenos de obras como Una mujer sin importancia y, sobre todo, la adaptación operística de Salomé fueron todo un acontecimiento de la época ${ }^{20}$.

\section{EL PÚBLICO}

En este complejo panorama, en el que participan los tres autores que nos sirven de guía, destacan unos pilares esenciales sobre los que se deben asentar estas líneas. De entrada, es evidente que Galdós tuvo mayores éxitos en el mundo teatral que Pardo Bazán y Clarín, aunque también él vivió sonoros fracasos. Ello mismo fue un incentivo para que ni una ni otros dudaran a la hora de opinar sobre ese universo teatral que en ocasiones les daba caprichosamente la espalda.

Para Pardo Bazán, gran parte del problema se hallaba en la existencia de un público de gustos vulgares, amigo de piezas intrascendentes y banales donde la música se combinaba con el enredo y el espectáculo esencialmente bufo. De tal manera, amargamente, lo denuncia en numerosas crónicas periodísticas ${ }^{21}$. Es una decepción

\footnotetext{
${ }^{20}$ Como muestra, consúltense los siguientes trabajos de Pardo Bazán: «Bohemia literaria», $A B C, 5$ de enero de 1910, edición de Marisa Sotelo, 2006: 131; "Cartas de la Condesa. De Teatros (En Flandes se ha puesto el sol de Marquina; el tríptico Misterio de Soraya; el Teatro Español) », Diario de la Marina, 22 de enero de 1911; pág. 113; «La vida contemporánea», IA, 27 de mayo de 1912, número 1587, pág. 350, pág. 469 de la edición facsimilar; «La vida contemporánea», IA, 23 de junio de 1913, número 1643, pág. 410, pág. 498 de la edición facsimilar; «La vida contemporánea», IA, 1 de junio de 1914, número 1692, pág. 366, pág. 462 de la edición facsimilar; «Carta de la Condesa. Obras teatrales: El hombre que asesinó, melodramas, la indiferencia del público», Diario de la Marina, 27 de febrero de 1915; pp. 270-271; «La vida contemporánea», IA, 17 de mayo de 1915, número 1742, pág. 334, pág. 556 de la edición facsimilar; «Crónicas de España», miércoles 12 de diciembre de 1917, pág. 6, en La Nación de Buenos Aires, edición de J. Sinovas Maté, tomo II, págs. 1223-1224 de la edición; etc.

${ }^{21}$ «Los actores portugueses», La Ilustración Ibérica, número 60, 23 de febrero de 1884, pág. 123 (en Patiño Eirín -ed.-, 2008: 232); «Realidad, drama de don Benito Pérez Galdós», Nuevo Teatro Crítico, año II, número 6, abril de 1892, pág. 22; «Crónica. Teatros y público», en La Nación, Buenos Aires, domingo 6 de junio de 1909; "Cartas de la Condesa. La temporada teatral en Madrid: los hermanos Quintero, La Esclava de Oliver», Diario de La Marina, 23 de enero de 1910, pág. 58 de la edición; «Crónicas de la condesa. Dos géneros: la comedia apacible y el drama simbólico social», 20 de marzo de 1910; pág. 68; «Crónica de España», en La Nación, Buenos Aires, 29 de abril de 1911, cito por la edición de Juliana Sinovas Maté, p. 523-524; «Crónicas de España», en La Nación, Buenos Aires, 8 de julio de 1911; cito por la edición de Juliana Sinovas Maté, p. 540; «Crónicas de España», en La Nación, Buenos Aires, 8 de abril de 1913; cito por la edición de Juliana Sinovas Maté, p. 767; «Crónicas de España. Cinematógrafos y teatros», en La Nación, Buenos Aires, 27 de diciembre de 1913; cito por la edición de Juliana Sinovas Maté, p. 852.
} 
común (y más temprana) en Galdós ${ }^{22}$. Este último ataca en varias ocasiones los espectáculos conocidos como «buffos» (género que tuvo como destacado cultivador a Arderius) que para él sobresalen por sus «pocas pretensiones literarias» ${ }^{23}$. También lo comentaba Clarín. Galdós lamenta, por ejemplo, la inclinación del púbico hacia obras extranjeras por la mera novedad, aunque estas fuesen de calidad cuestionable (carta en La Prensa de Buenos Aires, 22 de junio de 1882), y considera que polémicas ajenas al texto teatral puedan interferir en su interpretación (como lo hace notar ante La Piedad de una Reina, Carta en La Prensa de Buenos Aires, 2 de abril de 1887). En cuanto al público, lo cataloga de «timorato» $\mathrm{y}$, a veces, «fiera». Y sin embargo Galdós destaca la importancia de agradar al público ${ }^{24}$. Hemos de decir que esta postura no es uniforme, y que Galdós se queja, como Pardo Bazán y Clarín, de la existencia de una audiencia escasamente preparada para disfrutar de una buena obra teatral, como así deja testimonio (a ratos, con verdadera acritud) en carta a María Guerrero de 22 de junio de $1895^{25}$.

\footnotetext{
${ }^{22}$ Carta en La Prensa de Buenos Aires, 25 de abril de 1884). Véanse también Nuestro Teatro, pp. 137, 155; o El caballero encantado, pág. 96. Estas críticas son tempranas, pues se perciben ya en Crónica de Madrid en 1866 (como así señala Díaz Larios, 2002: 15). Su visión crítica alcanza géneros diversos, desde el operístico (y aquí comprobamos sus refinados gustos y su interés por la ópera, como ocurre en numerosas colaboraciones en La Nación. Diario progresista: así, las de 3 y 9 de febrero de 1865, 16 de febrero de 1865, 23 de marzo de 1865, 30 de marzo de 1865, 6 de abril de 1865, 3 de mayo de 1865..., donde incluye reflexiones sobre como Rigoletto, Guillermo Tell, El barbero de Sevilla, Fausto, compositores de la talla de Donizetti, Rossini y Strauss, o intérpretes como La Patti o Baragli) hasta otros más populares, dígase por ejemplo el circo («Circo del Príncipe Alfonso», en «Folletín. Revista de la semana», La Nación. Diario Progresista, 18 de mayo de 1865). Y finalmente, entrevemos sus quejas ante el tipo de representaciones intrascendentes que se llevan a las tablas, ya que habla de «espectáculos baratos, frívolos y cortos» (pág. 93 de Obras inéditas. Arte y política, ed. de Alberto Ghiraldo, 1923), y reseña negativamente obras como Los lirios del olvido («El verano se despide. Lucha de las estaciones (...)», «Folletín. Revista de la semana», La Nación. Diario Progresista, 10 de septiembre de 1865), Las querellas del Rey Sabio («Lord Palmerston. Desastres (...)», «Folletín. Revista de la semana», La Nación. Diario Progresista, 22 de octubre de 1865), El suplicio de una mujer («El suplicio de una mujer», «Folletín», La Nación. Diario Progresista, 3 de diciembre de 1865), La muerte de César («Príncipe. La muerte de César. Circe (...)»,«Folletín. Teatros», La Nación. Diario Progresista, 4 de marzo de 1866) o Juan Lorenzo («Un charco de ranas. Movimiento de la política (...)», «Revista de la semana», La Nación. Diario Progresista, 5 de noviembre de 1865).

23 «Revista de Madrid», La Nación. Diario Progresista, 2 de enero de 1868; el autor se alegrará ante la marcha de la representación de estas obras a Portugal: «Revista de la semana», La Nación. Diario Progresista, 29 de marzo de 1868.

${ }^{24}$ «Prólogo a Los condenados», pág. VII. El autor se manifiesta mucho más autocrítico que Pardo Bazán.

${ }^{25}$ Galdós considera que ningún autor debería someterse al criterio caprichoso de su público. Esta claudicación perjudica, a su modo de ver, a la obra del Duque de Rivas («El Duque de Rivas. Variedades. La Civili (...)», en «Folletín. Revista de la semana», La Nación. Diario Progresista, 2 de julio de 1865). O, alabando el Don Juan de Zorrilla, cuestiona el final aduciendo las siguientes palabras: «Este es el escollo que el poeta debía haber evitado, negándose a las exigencias de aquella parte inocente del público, que quiere que todo acabe bien y haya boda, aunque sea en el cielo» (Carta en La Prensa de Buenos Aires, 3 de diciembre de 1886). Para Galdós, el público favorece obras sencillas, de «pasajero atractivo» («Herir en la sombra, drama de los sres. Hurtado y Núñez de Arce», «Folletín. Revista de la semana», La Nación. Diario Progresista, 25 de marzo de 1866). Quiero terminar recordando las siguientes palabras del autor, que a mi modo de ver resumen su pensamiento: «iCon cuánta facilidad, Dios mío, se domestica, se encadena, se oprime y se esclaviza a ese gran monstruo que se llama público (...). ¡ Terrible alimaña es el público, es cierto; pero hay algunos que tienen el secreto de fascinarla como un rumor a la serpiente de cascabel!» («Revista de la semana», La Nación. Diario Progresista, 9 de febrero de 1868).
} 
Sumario detallado de la postura de don Benito son sus palabras en los trabajos recopilados en Nuestro Teatro ${ }^{26}$; allí, en síntesis, reitera las causas de los males que aquejan a la producción dramatúrgica de su momento. En Clarín y Pardo Bazán encontramos pensamientos similares, a saber: la proliferación de obras de ínfima calidad; la preferencia y delectación del público ante dichos engendros; la necesidad de actores adecuadamente preparados ${ }^{27}$; la escasa sensibilidad artística de la clase burguesa, público mayoritario de los teatros; el dominio de temas intrascendentes, con no más «que media docena de asuntos» (155), los cuales, con leves variantes, se repetían crónicamente; y la depauperación progresiva del lenguaje empleado en tales textos. Sangrante, en suma, es la falta de preparación para los gustos escénicos, para su estética, de las elites, como concomitantemente señala Clarín ${ }^{28}$; una espiral perniciosa, pues del público depende la supervivencia del teatro ${ }^{29}$.

Otra cuestión es el papel de la crítica, un grupo escasamente formado con múltiples defectos: arribismo, parcialidad y deficiente preparación. Son males que sólo se pueden combatir con un objetivo claro: la formación del público ${ }^{30}$.

Significativamente, como así consideraba Galdós, Clarín cree que, por ejemplo, el criterio del público es soberano por encima de lo que diga la crítica ${ }^{31}$. Tampoco debe extrañarnos que en su afán polemista, no siembre inocuo y a veces inicuo, cargado a ratos por su intención abiertamente declarada de polemizar, ataque el criterio de periódicos como El Independiente ${ }^{32}$; de El Globo de la mano de Revilla ${ }^{33}$; de Peregrín García Cadena; de Zeda en La Época; Arimón en El Tiempo, El Siglo o El Liberal; de Canals con su obra El año teatral (1896); Bonafoux; o de tantas otras publicaciones periódicas que dejan las secciones de crítica en manos de neófitos inexpertos y favorecen la escritura rápida y espontánea carente de rigor y método ${ }^{34}$. Aquí nace su principal denuncia: no existe una carrera profesional para el crítico literario y, para colmo de males, esta labor está mal pagada. La relación entre obra y público debería mirar a una crítica moderna inspirada en Emile Hennequin (1859-1888), según Clarín. Hennequin parte de Taine

\footnotetext{
${ }^{26}$ Recordemos que agrupa varios trabajos de Galdós entre 1885 y 1887, recogidos y publicados por A. Ghiraldo en 1923.

${ }^{27}$ La interpretación «empequeñece las obras o las agranda (...). Una obra dramática es como un cuerpo desnudo, que lucirá más o menos, según el corte o la elegancia del vestido con que se le presente» (pág. 167). Debo señalar que, años antes, ya lamentaba el autor la ausencia de un decidido relevo generacional en el mundo de los actores («La feria. Teatros», «Folletín. Revista de la semana», La Nación. Diario Progresista, 1 de octubre de 1865).

${ }^{28}$ Véase, por ejemplo, un artículo de sus últimos años: «Revista literaria», Los Lunes de El Imparcial, 24 de enero de 1898.

29 «Revista mínima», La Publicidad, 6944, 9 de febrero de 1898.

30 «Palique», La Unión, 373, 14 de diciembre de 1879.

${ }^{31}$ «Movimiento científico y artístico», La Unión, 350, 18 de noviembre de 1879.

32 «Palique», La Unión, 355, 23 de noviembre de 1879

33 «Echegaray y los críticos», La Unión, 380, 23 de diciembre de 1879; y 381, 24 de diciembre de 1879.

34 «Palique», El progreso, 346, 14 de abril de 1882; «Carta a un sobrino disuadiéndole de tomar la profesión de crítico», Nueva campaña.
} 
para crear una teoría crítica sólida de la obra artística, una ciencia de la obra de arte. $\mathrm{O}$ lo que es lo mismo, un procedimiento riguroso frente a la parcialidad y los posos tendenciosos y subjetivos que muy asiduamente mostraban los críticos literarios de la prensa española.

La crítica sale mal parada de la visión de los tres autores, y el público se consolida en valoraciones ambivalentes, como ser feroz que dictamina la supervivencia o demonización de un creador. Hablan de un público antojadizo, de gustos inestables, exigente, en el que con todo hay que distinguir una minoría formada y selecta frente al gran vulgo. Este último, indocto ante las cualidades del teatro, es propenso al chascarrillo o a la trama sentimentaloide, con la complicidad de la crítica periodística complaciente y escasamente formada que hace poco presentábamos. Ante ello, la necesidad de una regeneración teatral se proclama en numerosas ocasiones. Como muestra, pensemos en que lo hace el Clarín de los primeros tiempos, reivindicando la recuperación de la fantasía y la imaginación frente a un teatro anquilosado y estático y un público antojadizo ${ }^{35}$. Muestra paradigmática es también «El teatro anémico» (El progreso, 9 de octubre de 1882), si bien no el único ${ }^{36}$. Es especialmente combativo en sus artículos de la década de los 80, donde asume como esperanzadoras las reformas anunciadas por el Teatro Español. Pero la temporada de 1882 le deja un sabor amargo ante la evidencia de que se perpetran y perpetúan las mismas mediocridades. Esta mención nos permite introducir la última piedra que carga al teatro del momento, una vez expurgados los pecados de crítica y público. El aliento del declive procede asimismo de la existencia de un amplio elenco de autores «advenedizos», recién llegados sin dotes. Con ellos se produce un fenómeno curioso, un sentimiento corporativista en torno a su identidad como creadores $^{37}$. Público, crítica y autores son la tríada que sostiene a un teatro convaleciente en permanente y enfermizo sopor.

\section{LOS MODELOS}

Ante este teatro que desfallece en lenta y constante agonía se plantea la necesidad de la reforma que sanee el sistema corrompido, paralizado y decadente. Los autores pretenden una nueva modelización de los postulados dramatúrgicos en auge.

Con Galdós observamos la inclinación por obras como La campana de la Almudaina de Valero o La mujer de Ulises de Blasco ${ }^{38}$, o por autores como Hartzenbusch o Bretón de

\footnotetext{
${ }^{35}$ «Libros y libracos», El Solfeo, 79, 17 y 18 de noviembre de 1875; «Teatros», La Unión, 92, 12 de noviembre de 1878.

${ }^{36}$ «Del teatro», Solos de Clarín, donde reflexiona sobre la ineficiencia de las conocidas como tres unidades (lugar, tiempo, acción) o la creación de caracteres; Rafael Calvo y el teatro español. Folleto literarios; «El teatro en barbecho», Siglo pasado.

37 «El amigo del drama», El Día, 946, 1 de enero de 1883.

38 «Revista de la semana», La Nación. Diario Progresista, 15 de octubre de 1865.
} 
los Herreros ${ }^{39}$. Defiende la recuperación de los clásicos, ante la ignorancia o desinterés de los creadores por ellos (los del Siglo de Oro, también los románticos).

Clarín, por su parte, llama la atención en 1879 sobre la ausencia de un auténtico interés nacional por nuestro legado dramatúrgico. Este desinterés es suplido por el gusto y la atracción de investigadores extranjeros, en especial ingleses y alemanes ${ }^{40}$. También Clarín considera positivo (no siempre) el modelo de Hartzenbusch, y parcialmente Tamayo con su Un drama nuevo (y no el autor que, para él, mostraba un lenguaje poco natural y recursos artificiosos) ${ }^{41}$, Echegaray (con matices) ${ }^{42}$, Ayala ${ }^{43}$, Sellés, García Gutiérrez, o Zorrilla ${ }^{44}$. Coincide con Galdós en la necesaria recuperación de los autores clásicos, los modelos que sirvan de guía en un nuevo camino de renovación y cambio, como Plauto $^{45}$ o, ya en nuestro legado cultural, Calderón.

¿Y Pardo Bazán? Pues ella ahonda en lo mismo, en el dolor ante el teatro en estado de descomposición. Continúa, en el siglo $\mathrm{XX}$, con su denuncia de los triunfos hirientes de obras de baja calidad, un insulto ofensivo para las grandes obras que fracasaban estrepitosamente. En este momento manifiesta sus preferencias por el teatro de Galdós ${ }^{46}$ y, con un interesante halo de vanguardia y modernidad, por ValleInclán ${ }^{47}$. Ello le vale para tratar viejos asuntos, resaltando una y otra vez el carácter

\footnotetext{
39 «Galería de españoles célebres», «Folletín», La Nación. Diario Progresista, 4 de febrero de 1866; «El abogado de los pobres, de D. Manuel Bretón de los Herreros», «Folletín. Teatros», La Nación. Diario Progresista, 11 de febrero de 1866.

40 «Libros», La Unión, 113, 2 de enero de 1879.

${ }^{41}$ «Palique», La Unión, 293, 12 de septiembre de 1879; «Echegaray y los críticos», La Unión, 380, 23 de diciembre de 1879; «Tamayo», La Correspondencia de España, 1 de julio de 1898; «Revista mínima», La Publicidad, 7093, 8 de julio de 1898; «Le mouvement Littéraire contemporain», L’Espagne, numéro spécial encyclopedique de la Nouvelle Revue Internacional, Paris, $2^{\circ}$ semestre 1900 (véase "Auteurs dramatiques»).

42 «Literatura dramática», El Eco de Asturias, 1916, 15 de marzo de 1875; «Echegaray en provincias», El Solfeo, 479, 9 de febrero de 1877; «Teatros», El Solfeo, 653, 654 y 655 (15, 16 y 17 de octubre de 1877); «Teatros», La Unión, 99, 29 de noviembre de 1878; «Noticias teatrales», La Unión, 379, 21 de diciembre de 1879; y 381, 24 de diciembre de 1879; «Noticias teatrales», El mundo moderno, 22, 20 de marzo de 1881; «Noticias teatrales», El mundo moderno, 33, 2 de abril de 1881; «Madrileñas», La Publicidad, 1135, 5 de abril de 1881; «Noticias teatrales», El mundo moderno, 36, 6 de abril de 1881; «Madrileñas», La Publicidad, 1383, 8 de diciembre de 1881; «Estrenos», El Progreso, 589, 15 de diciembre de 1882; «Un crítico incipiente», Madrid Cómico, 424, 4 de abril de 1891; «Revista literaria», Las Novedades, 681, 28 de marzo de 1895; «Mar sin orillas (Echegaray) », Solos de Clarín; «Haroldo el normando», La literatura en 1881; «Sobre motivos de un drama de Echegaray», La literatura en 1881.
}

${ }^{43}$ «Noticias teatrales», La Unión, 396, 11 de enero de 1880; «Consuelo (Ayala)» (en Solos de Clarín).

${ }^{44}$ «El teatro de Zorrilla», Palique.

45 «Palique», La Unión, 373, 14 de diciembre de 1879.

46 «Crónicas de la condesa. Dos géneros: la comedia apacible y el drama simbólico social», La Nación de Buenos Aires, 20 de marzo de 1910, pág. 68; «Crónicas de España. Cinematógrafos y teatros», La Nación de Buenos Aires, sábado 27 de diciembre de 1913, pág. 9; «Carta de la condesa», Diario de la Marina, 9 de marzo de 1914, pp. 247-252 de la edición de Cecilia Heydl-Cortínez.

${ }^{47}$ «Cartas de la Condesa. El embrujado de Valle-Inclán; la ópera española: Tabaré de Bretón», Diario de la Marina, 23 de marzo de 1913; pp. 207-208. 
imprevisible del público ${ }^{48}$. Llama la autora a la innovación y al cambio, a la vez que asume que la adaptación de textos clásicos es la apuesta menos arriesgada ${ }^{49}$. El realismo del teatro de Galdós y su interés por reflejar problemas de conciencia individual (frente a la intrascendencia de gran parte de los textos del momento) parece influir en Pardo Bazán, a través de obras como Realidad ${ }^{50}$. En ambos hay un reconocimiento explícito de la importancia de la tradición literaria (en especial la de los Siglos de Oro ${ }^{51}$ ) y reflejan el magisterio de Ibsen ${ }^{52}$ (mayor, tal vez, en Pardo Bazán), pero también de forma indirecta de Kierkegaard ${ }^{53}$. No digamos además de Echegaray ${ }^{54}$, por cuyo aprecio (ya reseñado

\footnotetext{
${ }^{48}$ «La vida contemporánea. Adonde va la gente», La Ilustración Artística, número 950, 12 de marzo de 1900.

49 «Crónicas de España. Cinematógrafos y teatros», sábado 27 de diciembre de 1913, pág. 9, en La Nación de Buenos Aires, edición de J. Sinovas Maté, tomo II, pág. 852 de la edición.
}

${ }^{50}$ Véase, por ejemplo, lo que dice Prol Galiñanes (2001: 34 y ss.). Habría que extender dicha influencia, que alcanzaría otros textos menos comentados, caso de La loca de la casa, objeto de elogios por parte de Pardo Bazán («La loca de la casa», Nuevo Teatro Crítico, número 25, enero de 1893, pp. 84-108).

${ }^{51}$ Galdós, por ejemplo, alaba que se reestrenen textos como El alcalde de Zalamea, Lo cierto por lo dudoso o El desdén con el desdén («La feria. Teatros», «Folletín. Revista de la semana», La Nación. Diario Progresista, 1 de octubre de 1865). La representación de estos clásicos es para él una buena noticia («Variedades. Revista de teatros. Dos palabras sobre los teatros del Príncipe y Variedades (...)», La Nación. Diario Progresista, 6 de octubre de 1865). Prodigará elogios en lo que atañe a la figura de Calderón, denuncia el olvido al que están sometidas sus obras y considera que el teatro moderno se inspira en él («Variedades. El aniversario de Calderón», La Nación. Diario Progresista, 17 de enero de 1868). En Pardo Bazán, encontramos abundante muestra de este aprecio en La Ilustración Artística, por ejemplo (caso de los números 746 ó 1726, entre otros muchos).

${ }^{52}$ Sobre el influjo de Ibsen sobre Galdós véase, por ejemplo, Sobejano (1970: 43) o Amor del Olmo (2006: 41-46). Galdós alude al magisterio del dramaturgo noruego en diversas ocasiones, como ocurre con el «Prólogo» de Los condenados (pp. XII-XIII). Sobejano habla, asimismo, en lo que toca a la producción teatral del autor canario, de «dramas de la separación, en los que el desenlace separa a los portadores del conflicto, ya sean éstos personas o actitudes; y dramas de la conciliación, en los que el desenlace concilia, de hecho o en esperanza, a los representantes del conflicto o de la diferencia» (ídem., pp. 44-45). A su juicio, forman parte del primer grupo Bárbara y Casandra. Como testimonio del interés de Pardo Bazán, indico el siguiente fragmento: «Y yo declaro que ni Ibsen ni Wagner me han parecido oscuros jamás; antes al contrario, expresivos y emocionantes en grado sumo; Ibsen, además, realista y verista, y observador concreto de la naturaleza y psicología humanas. Sus caracteres sangran verdad (...) Sus facultades dramáticas eran excepcionales (...) Lejos de ser pesado, uno de los méritos de Ibsen consiste en la rapidez y en la concentración. Ningún clásico observó mejor la unidad de tiempo, encerrando en breves notas la intensa acción dramática» («La vida contemporánea», pág. 2, La Ilustración Artística, número 1305, 1 de enero de 1907, cito por la edición de Carlos Dorado, 2005). Véanse también, por ejemplo, los números 1275 (pág. 362), 1319 (pág. 234), 1518 (pág. 78), 1539 (pág. 414), etc. Para el caso de verdad, véase Thion Soriano (2002: 243). En Clarín, véase por ejemplo «Ibsen y Daudet», Ensayos y revistas.

${ }^{53}$ Eoff (1966: 8) destaca, por ejemplo, el posible magisterio de Kierkegaard en Fortunata y Jacinta. He destacado en otra ocasión la influencia de este filósofo sobre Pardo Bazán (véase López Quintáns, 2008, capítulo dedicado a La Quimera).

${ }^{54}$ Además de responder a las críticas vertidas por Isaac Rubio por sugerir equivalencias entre el teatro de Ibsen y Galdós, Gonzalo Sobejano (1976) analiza los paralelismos con Echegaray, en especial entre Electra y Dos fanatismos. No compete aquí recordar las réplicas críticas entre Sobejano y Rubio, a propósito de las relaciones Galdós/Ibsen y Galdós/Echegaray. Valga, de momento, mi reconocimiento a la validez de los argumentos de ambos, pese a que se dejaron arrastrar más (como a veces parece) por un deseo de autoafirmación que de auténtica puntualización del análisis literario. En cualquier caso, reviste gran interés el trabajo de Rubio de 1981, para matizar la catalogación de Galdós como autor realista, autor melodramático o autor de personajes. La variedad de apreciaciones de Sobejano 
en Clarín) dejará testimonio Galdós en textos como los recopilados en Nuestro Teatro y Pardo Bazán en abundantes trabajos periodísticos, díganse los publicados en su Nuevo Teatro Crítico ${ }^{55}$.

\section{LOS ACTORES}

El cambio también suscita la implicación de nuevos participantes en el entremado, singularmente con natural preponderancia los actores. El buen comediante se convierte en sinónimo vivo de sentimiento en la recreación del papel, de naturalidad y elocuencia, de dicción morigerada y correcta, y constancia en la preparación e identificación con el personaje. Observamos a la par los defectos que deben evitar. Afirma Galdós de la gran Sarah Bernhardt que logra destacar en las escenas amorosas pero «en la parte trágica flaquea su talento» (Carta en La Prensa de Buenos Aires, 13 de noviembre de 1889). Una crítica similiar aparece en Pardo Bazán, en el capítulo sobre el teatro en Francia incluido en Por Francia y Alemania.

Prolífico es Clarín en la persecución y azote de mediocres actores: la señora Hinojosa en A la alta escuela, y esta y Mariano Fernández, a propósito de Salirse de sus esfera, de Golmerino y González ${ }^{56}$; o las actrices Marín y Chaman en El tanto por ciento de Ayala. Desentrañando las raíces de sus quejas llegamos a que el actor debe huir de la afectación. Ya en los 80, sus dardos ponzoñosos asaetean a la Gorriz de Sin familia de Miguel Echegaray; o a Cirera. Y en los 90, a Martos en sus papeles de Shakespeare, o a Donato Jiménez. Es de gran interés para comprender cómo se debe formar un buen actor el trabajo «Teatros» (El mundo moderno, 56, 30 de abril de 1881) de Leopoldo Alas. En este viene a decir que el teatro presenta dos resortes básicos: la obra, el texto; y las dotes de representación de los actores, si bien en lo segundo distingue una notable inferioridad del caso español con respecto a ingleses y franceses.

Galdós, Clarín y Pardo Bazán no lo dudan. Guerrero (entre las primeras damas, a partir de los artículos de los 90), Mendoza, Tubau, Vico o Mario son los grandes actores, aunque a veces merecen su reprobación. Clarín vuelve a ser muy prolífico

y Rubio creo que en el fondo demuestran la versatilidad de Galdós y la pluridimensionalidad de su teatro, donde son perceptibles diversas influencias, todas ellas ratificadas por el propio autor (como el interés por la obra de Ibsen o la inclinación por el teatro de Echegaray). Aún así, cabe señalar que Pardo Bazán tendió a considerar como escasas las similitudes entre Galdós-Echegaray («Carta de la condesa», Diario de la Marina, 9 de marzo de 1914, pág. 248 de la edición de Cecilia Heydl-Cortínez). También es crítica con Echegaray, cuando advierte rasgos que no son de su gusto («Revista de teatros. Los estrenos», Nuevo Teatro Crítico, año I, número 12, diciembre de 1892, pp. 52-53, a propósito de La credencial; «Revista de teatros», Nuevo Teatro Crítico, año I, número 13, enero de 1892, pp. 88 y ss., a propósito de Comedia sin desenlace; «Revista dramática», Nuevo Teatro Crítico, año II, número 18, junio de 1892, pp. 76-81; «El poder de la impotencia (estreno de Echegaray) », Nuevo Teatro Crítico, número 27, marzo de 1893, pp. 112-118).

${ }^{55}$ No sólo allí. Véase, por ejemplo, «El estreno de Echegaray (Siempre en ridículo) », Nuevo Teatro Crítico, año I, número 1, enero de 1891, pp. 75-84; «El estreno de "Mariana" de Echegaray», Nuevo Teatro Crítico, número 24, diciembre de 1892, pp. 49-84; «Crónica de España», en La Nación, Buenos Aires, 29 de abril de 1911, cito por la edición de Juliana Sinovas Maté, p. 523-524.

${ }^{56}$ «Noticias teatrales», La Unión, 359, 28 de noviembre de 1879. 
sobre el tema y manifiesta sus predilecciones y sus reparos, como con María Tubau; o Sara Bernhardt, modelo de actriz, ponderándose su capacidad gestual con motivo de su actuación en el Teatro Real en abril de $1882^{57}$. Sobre la figura de Bernhardt habla en numerosas ocasiones, se recrea en su capacidad de captar la esencia del papel que interpreta, en la naturalidad de su elocución o la belleza de sus gestos, bien es cierto que juzga que a veces transmite cierta frialdad y amaneramiento ${ }^{58}$. Contempla a otros, como Virginia Marini en La princesa Jorge de Alejandro Dumas hijo o Fuegos de paja de Linares Rivas ${ }^{59}$; Pía Marchi en Divorsiamo de Sardou; los Leigheb en La cadena de Scribe o Fuegos de paja; Cola en La dama de las camelias; Novelli... Son grandes que no crean escuela y no tienen continuidad, lo que lleva a que en los 90 anote la carencia de buenas actrices. Destellos sin seguimiento, como la gran María Guerrero que impresiona a Clarín al verla en la compañía de Mario. Escribe Teresa pensando en ella.

\section{CIERRE}

Los párrafos que preceden han aportado información sobre algunas de las disquisiciones de Galdós, Clarín y Pardo Bazán en torno al teatro que les tocó vivir. Con ellas, eran varios los puntos que pretendían ser resaltados. En pimer lugar, la evidencia de la multiplicidad de manifestaciones del momento, desde un teatro posromántico, pasando por melodramas, comedias de baja estofa, "buffos", piezas musicales, imitaciones o reposiciones de obras clásicas (en especial la de los Siglos de Oro) o piezas de trasfondo didáctico o moralizante.

En segundo lugar, se llamaba la atención acerca de las carencias de un panorama teatral aquejado de inmovilidad bajo el dominio de un público burgués de gustos conservadores y reaccionarios. Era un público de formación escasa para la degustación artística y de predilecciones inestables y cambiantes. En ello se percibía la responsabilidad de la crítica literaria en la prensa, carente de formación, en parte debido a la inexistencia de una carrera profesional y de la pobre remuneración del oficio.

\footnotetext{
57 «Noticias teatrales», El Solfeo, 796, 31 de marzo de 1878; «Teatros», La Unión, 437, 28 de febrero de 1880; «Estrenos», El Progreso, 596, 22 de diciembre de 1882; «Estrenos», El Progreso, 637, 2 de febrero de 1883; «Palique», Madrid Cómico, 403, 8 de noviembre de 1890; «Palique», Madrid Cómico, 404, 15 de noviembre de 1890; «Palique», Madrid Cómico, 407, 6 de diciembre de 1890; «Cosas del teatro», La Correspondencia de España, 18 de octubre de 1891 y 1 de noviembre de 1891; «Realidad», La Correspondencia de España, 17 de marzo de 1892; «María Guerrero», Los Apuntes, 2 y 3, 19 de julio y 26 de julio de 1894; «Revista literaria», Las Novedades, 710, 17 de octubre de 1895; «Palique», Madrid Cómico, 818, 22 de octubre de 1898; «Palique», Heraldo de Madrid, 5 de septiembre de 1899; «Un resumen», Pluma y Lápiz, 17, 24 de febrero de 1901. Además, representan sus obras (Tubau, por ejemplo, lleva a las tablas Cuesta abajo de Pardo Bazán, el 22 de enero de 1906).

58 «Palique», El Progreso, 351, 19 de abril de 1882; «Palique», La publicidad, 1516, 20 de abril de 1882; «Palique», El Progreso, 353, 21 de abril de 1882; «Madrileñas», La Publicidad, 1532, 6 de mayo de 1882; «Teatros», El Progreso, 415, 24 de junio de 1882; «Los Pirineos del arte. Sarah Bernhardt», ...Sermón perdido.

59 «Comedia», El Progreso, 365, 3 de mayo de 1882; «Comedia», El Progreso, 383, 22 de mayo de 1882; «Comedia», El Progreso, 384, 23 de mayo de 1882.
} 
Los autores mediocres campaban a sus anchas, en un panorama propenso a la aceptación de creadores ocasionales, aficionados de corta inspiración que se aprovechaban de un sistema propicio a los autores improvisados. La regeneración necesaria del teatro surgía como consecuencia lógica, bajo resortes bien definidos: preparación del público, innovación en temas y técnicas, formación adecuada de los autores y asentamiento de una carrera profesional en el ámbito de la crítica literaria. Los actores estaban también llamados al cambio, a la reforma y a la innovación.

Con estas líneas, terminamos esta aproximación al teatro del XIX. En un momento que brilla en esencia merced a otros géneros literarios, con mención de honor la novela, no deja de despertar sugestivas inspiraciones y comentarios la abundante producción teatral, pese a sus momentos habituales de mediocridad. Ahora bien, nuestro propósito por esta vez ha sido alcanzado. Se puede bajar el telón.

\section{BIBLIOGRAFÍA}

\section{A.Obras de Emilia Pardo Bazán , Benito Pérez Galdós y Leopoldo Alas «Clarín»:}

A1. De Pérez Galdós:

«Prólogo», en Los condenados: drama en tres actos, de Benito Pérez Galdós, Madrid, Imprenta de José Rodríguez, 1895, pp. V-XXVIII.

Nuestro teatro. Obras inéditas, de Benito Pérez Galdós, edición de Alberto Ghiraldo, Madrid, Renacimiento, 1923-31, volumen V.

Obras inéditas. Arte y política, edición de Alberto Ghiraldo, Madrid, Renacimiento, 1923, volumen II.

Los artículos de Galdós en La Nación. 1865-1866, 1868, edición de William H. Shoemaker, Ínsula, Madrid, 1972.

Las cartas desconocidas de Galdós en la prensa de Buenos Aires, edición de William H. Shoemaker, Ediciones de Cultura Hispánica, Madrid, 1973.

Galdós, periodista, Madrid, Banco de Crédito Industrial, 1981.

El Caballero encantado, ed. Julio Rodríguez-Puertolas, Madrid, Cátedra, 1982.

Bárbara. Casandra. Celia en los infiernos, de Benito Pérez Galdós, edición de Rosa Amor del Olmo, Madrid, Cátedra, 2006.

\section{A2. De Pardo Bazán:}

El lirismo en la poesía francesa, Madrid, Editorial Pueyo, [s.a.].

Verdad (pp. 1608-1634), en Obras completas. Novelas y cuentos, de Emilia Pardo Bazán, tomo II, edición de F. C. Sáinz de Robles, Madrid, Aguilar, 1964. 
Cuesta abajo, Las raíces, de Emilia Pardo Bazán, edición de María Prado Mas, Madrid, Publicaciones de la asociación de directores de escena de España, 2002.

Emilia Pardo Bazán. La obra periodística completa en La Nación de Buenos Aires (1879-1921), edición de J. Sinovas Maté, Salamanca, Diputación Provincial de A Coruña, 1999, 2 vols.

Cartas de la Condesa en el Diario de la Marina. La Habana (1909-1915), edición de C. HeydlCortínez, Madrid, Editorial Pliegos, 2002.

La vida contemporánea, de Emilia Pardo Bazán, edición facsimilar de C. Dorado, Madrid,

Hemeroteca municipal de Madrid, Testimonio de prensa, número 5, 2005.

Un poco de crítica. Artículos en el ABC de Madrid (1918-1921), de Emilia Pardo Bazán, edición de Marisa Sotelo Vázquez, Alicante, Publicaciones de la Universidad de Alicante, 2006.

Por Francia y Alemania, Madrid, La España Editorial, 1899.

\section{A3. De Clarín.}

Crítica, tomo IV, ed. de Laureano Bonet, Madrid, Nobel, 2003.

Artículos, tomo V, edición de Jean-François Botrel e Yvan Lissorgues, 2002.

Artículos, tomo VI, edición de Jean-François Botrel e Yvan Lissorgues, 2003.

Artículos, tomo VII, edición de Jean-François Botrel e Yvan Lissorgues, 2004.

Artículos, tomo VIII, edición de Jean-François Botrel e Yvan Lissorgues, 2005.

Artículos, tomo IX, edición de Jean-François Botrel e Yvan Lissorgues, 2005.

Artículos, tomo X, edición de Jean-François Botrel e Yvan Lissorgues, 2006.

\section{B. Estudios sobre su obra (selección):}

Abuín, Á. (1998): «Las culpas traen las penas: El héroe melodramático en el teatro de E. Pardo Bazán», en Jesús G. Maestro (ed.), El personaje teatral, Vigo, Universidade de Vigo. Servicio de Publicacións.

Amor del Olmo, R. (2006): Introducción, en Bárbara/Casandra/Celia en los infiernos, de Benito Pérez Galdós, Madrid, Cátedra, pp. 11-155.

AAVV, (1998): Los estrenos teatrales de Galdós en la crítica de su tiempo, edición de Ángel Berenguer, Comunidad de Madrid, Consejería de Cultura.

Beser, S. (1968): Leopoldo Alas, crítico literario, Madrid, Gredos.

Bretz, M. L. (1984): «The Theater of Pardo Bazán and Concha Espina», Estreno, 10, pp. 43-45.

De Val, M. M. (1906): Los novelistas en el teatro. Tentativas dramáticas de Da Emilia Pardo Bazán, Madrid, Bernardo Rodríguez. 
Díaz Larios, L. F. (2002): Introducción, en La de San Quintín/Electra, de Benito Pérez Galdós, Madrid, Cátedra, pp. 11-103.

Eoff, S. (1966): «Galdós in Nineteenth Century Perspective», Anales Galdosianos, I, pp. 4-10.

García Castañeda, S. (1997): «El teatro de Emilia Pardo Bazán: estado de la cuestión», en J. M. González Herrán (ed.), Estudios sobre Emilia Pardo Bazán. In Memoriam Maurice Hemingway, Santiago de Compostela, Universidade de Santiago de Compostela. Consorcio de Santiago, pp. 133-154

García Castañeda, S. (2008): «Emilia Pardo Bazán: su teatro, sus críticos y su público» en José Manuel González Herrán, Cristina Patiño y Ermitas Penas (eds.), Actas del IV Simposio Emilia Pardo Bazán: «Emilia Pardo Bazán y las artes del espectáculo», A Coruña, Real Academia Galega, pp. 133-154.

Gómez de Baquero, E. (1905): «El teatro de Galdós», Letras e ideas, Barcelona, Henrich, pp. 192-203.

González González, M. M. y Rosa María Cid López (eds.) (2003): Mitos femeninos de la cultura clásica: creaciones y recreaciones en la historia y la literatura, Oviedo, Krk Ediciones, pp. 152-182.

González Herrán, J. M. (2002): «Clarín y la sociedad literaria de su tiempo: estado de la cuestión», Leopoldo Alas : un clásico contemporáneo (1901-2001).Tomo I. Actas del Congreso celebrado en Oviedo (12-16 de noviembre de 2001), Oviedo, Universidad, pp. 203-218.

Hernández, L. (1992): "Clarín, Galdós y Pardo Bazán frente al teatro de Echegaray», Anales de Literatura Española de la Universidad de Alicante, 8, pp. 95-108.

Lissorgues, Y. (1996): El pensamiento filosófico y religioso de Leopoldo Alas, Clarín, Oviedo, Grupo Editorial Asturiano.

Lissorgues, Y. (2004): Clarín político, Oviedo, KRK.

López Quintáns, J. (2006): «Pardo Bazán y el teatro: el caso de Cuesta abajo», Moenia, nº 12, pp. 305-317.

López Quintáns, J. (2007): «El rostro, ambiguo espejo del alma: descripciones masculinas y femeninas en la obra de Emilia Pardo Bazán», La Tribuna. Cuadernos de Estudios da Casa Museo Emilia Pardo Bazán, 5, pp. 237-271.

López Quintáns, J. (2008): «¿Resignación o rebeldía? Reflexiones sobre Las Raíces de Emilia Pardo Bazán», Revista de Filología. Universidad de la Laguna, 26, pp. 95-102. López Quintáns, J. (2008b): El fracaso existencial en los personajes de la narrativa de Emilia Pardo Bazán, Madrid, Fundación Universitaria Española.

Martínez Cachero, J. M. (1983): «La actitud anti-modernista del crítico “Clarín"», Anales de Literatura Española, núm 2, pp. 383-398.

Martínez Cachero, J. M. (1991): Luis Bonafoux/Leopoldo Alas. Hijos de la crítica, Oviedo, Grupo Editorial Asturiano. 
Nieva, F. (1989): «Una mirada sobre el teatro de Emilia Pardo Bazán», en Marina Mayoral (coord.), Estudios sobre «Los Pazos de Ulloa», Madrid, Cátedra, pp. 189201.

Patiño Eirín, C. (2008): «Trashumancias de Talía: actores y actrices según Emilia Pardo Bazán», en José Manuel González Herrán, Cristina Patiño y Ermitas Penas (eds.), Actas del IV Simposio Emilia Pardo Bazán: «Emilia Pardo Bazán y las artes del espectáculo», A Coruña, Real Academia Galega, pp. 189-242.

Pattison, W. T. (1973): «Two women in the life of Galdós», Anales Galdosianos, VIII, pp. 24-32.

Percival, A. y J. Escobar (1984): «De la tragedia al melodrama», Romanticismo 2: Il lingguaggio romantico, Genova: Università di Genova, pp. 141-146.

Pérez Rasilla, E. y Soria, G. (2005): «El teatro de Chéjov en España. Una historia que transcurrió despacio», Revista de la Asociación de directores de escena de España, 104, pp. 91-105.

Prol Galiñanes, T. M. (1999): Un legado teatral marginado en nuestra historia literaria: la obra dramática de Pardo Bazán, T.A.D. inédito dirigido por el profesor J. M. González Herrán.

Ribao Pereira, M. (2005): «Documentos para el estudio del teatro de Emilia Pardo Bazán», en González Herrán, Patiño y Penas (eds.), Actas del I Simposio Emilia Pardo Bazán: «Emilia Pardo Bazán: estado de la cuestión», A Coruña, Real Academia Galega, pp. 113-134.

Ribao Pereira, M. (2006): «Doña Emilia también dramaturga: la literatura al servicio del texto teatral», La Tribuna. Cadernos de Estudos da Casa Museo Emilia Pardo Bazán, 6, pp. 253-270.

Romero Tobar, L. (2002): «Clarín, el ojo y el oído del crítico teatral», en Antonio Vilanova y Adolfo Sotelo Vázquez (eds.), Leopoldo Alas, Clarín, Actas del simposio internacional, pp. 8-123.

Rubio, I. (1981): «Galdós y el melodrama», Anales Galdosianos, año XVI, pp. 58-66.

Rubio, I. (1983): «El teatro de Galdós», Anales Galdosianos, año XVIII, pp. 139-145.

Sánchez, R. G. (1963): «Clarín y el Romanticismo Teatral: examen de una afición». Hispanic Review, 31, pp. 216-228.

Sánchez, R. G. (1969): «The Presence of Theater and the Consciousness of Theater in Clarín's La Regenta». Hispanic Review, 37, pp. 491-509.

Sobejano, G. (1965): «Clarín y la crisis de la crítica satírica», Revista Hispánica Moderna, 31, 1-4, p. 399.

Sobejano, G. (1970): «Razón y suceso de la gramática galdosiana», Anales Galdosianos, V, pp. 39-54.

Sobejano, G. (1976): «Echegaray, Galdós y el melodrama», Anales Galdosianos, Anejo, pp. 91-116. 
Schiavo, L. y Á. Mañueco Ruiz (1990): «El teatro de Emilia Pardo Bazán: documentos inéditos», en Kathleen N. March, Homenaxe a Ramón Martínez López, A Coruña, Ediciós do Castro. Publicacións do Seminario de Estudos Galegos, pp. $55-72$.

Tolivar Alas, A. C. (1998): «Clarín y el teatro lírico», 50 Aniversario de la Ópera de Oviedo, Oviedo, Casaprima, pp. 27-46.

Tolivar Alas, A. C. (2001): «El teatro juvenil de Leopoldo Alas», Clarín, 100 años después: un clásico contemporáneo, Alcalá de Henares (Madrid), Instituto Cervantes, pp. 113-123.

Thion, D. (2002): «Verdad-Verité, génesis y trayectoria de un manuscrito», Iris, Montpellier, pp. 233-248. 